\title{
AWARENESS ON HEALTH INSURANCE AMONG AN URBAN COMMUNITY IN IMPHAL: A CROSS- SECTIONAL STUDY
}

\author{
Haobam Danny Singh ${ }^{1}$, Sanjay Rudrapal2 ${ }^{2}$ Rosswel JB Sangma ${ }^{3}$
}

${ }_{1}^{1}$ Post Graduate Trainee, Department of Community Medicine, Regional Institute of Medical Sciences, Imphal.

2 Post Graduate Trainee, Department of Community Medicine, Regional Institute of Medical Sciences, Imphal.

${ }^{3}$ Post Graduate Trainee, Department of Community Medicine, Regional Institute of Medical Sciences, Imphal.

\section{ABSTRACT}

\section{BACKGROUND}

More than $70 \%$ of health care expenditure in India today is met out of individuals' pocket. In this scenario, health insurance is emerging as an alternative mechanism for financing of health care. Literature regarding awareness on health insurance in Mani pur is lacking.

\section{OBJECTIVES}

1. To determine the level of awareness as well as the perception and practice about health insurance among an urban community.

2. To determine the association between awareness on health insurance with select demographic variables.

\section{METHODS}

This was a cross-sectional study conducted among 201 families in Thangmeiband Sinam Leikai, Imphal West. Participants were either head of the family or any responsible family member above the age of 18 years who were present at the time of visit. Data were collected by interviewing the participants using a semi-structured questionnaire. Data entry were done using SPSS version 21 (IBM). Descriptive statistics like mean, median, percentages and proportion were used. Test of association were done using Chisquare and t-test.

\section{RESULTS}

$62.7 \%$ (126) of the respondents were aware of health insurance and the major sources of information about health insurance were provided by friends and relatives (33.8\%) followed by insurance agents (26.9\%). Only 9.5\% of those who were aware of health insurance had an existing health insurance scheme. Higher Educational level and higher Socio-economic status of the respondents were found to be significantly associated with more awareness on health insurance.

\section{CONCLUSION}

Awareness about health insurance was satisfactory, but it did not lead to increased enrolment. There is a need to reinforce information, education and communication campaign about health insurance among the general population.

\section{KEYWORDS}

Health Insurance, Awareness, Insurance Agents.

HOW TO CITE THIS ARTICLE: Singh HD, Rudrapal S, Sangma RJB. Awareness on health insurance among an urban community in Imphal: a cross-sectional study. J. Evolution Med. Dent. Sci. 2016;5(27):1383-1386, DOI: 10.14260/jemds/2016/326

\begin{abstract}
INTRODUCTION
India with a population of 1.2 billion possesses around $16.6 \%$ of the global population and $20 \%$ of the global disease burden. India spends about $4.9 \%$ of its GDP on health, out of which $0.9 \%$ were Public and $4 \%$ Private. Of the private expenditure, $3.6 \%$ were Out Of Pocket (OOP) expenditure. Thus, more than $70 \%$ of health care expenditure in India today is met out of individuals' pocket. The decline in public investment in health and the absence of any form of social insurance have heightened insecurities. The unpredictability of illness requiring substantial amounts of money at short notice are improvising an estimated 3.3\% of India's population every year.
\end{abstract}

Financial or Other, Competing Interest: None.

Submission 15-02-2016, Peer Review 09-03-2016,

Acceptance 16-03-2016, Published 01-04-2016.

Corresponding Author:

Haobam Danny Singh,

Department of Community Medicine,

Regional Institute of Medical Sciences,

Imphal.

E-mail: haobamdanny@yahoo.com

DOI: $10.14260 /$ jemds/2016/326
The poorest $10 \%$ of the population rely on sales of their assets or on borrowings, entailing inter-generational consequences on the family's ability to access basic goods and affecting their long-term economic prospect. ${ }^{1}$ Given the implication that a healthy and productive population has on economic development, there is a need to step up health care funding mechanism. In this scenario, health insurance is emerging as an alternative mechanism for financing of healthcare. It works on the basic principle of pooling of risks of unexpected costs of persons falling ill and needing hospitalisation by charging premium from a population.

A study conducted among an urban community in Mangalore city by Reshmi B et al. ${ }^{2}$ reveals that $64 \%$ of the respondents were aware of any forms of health insurance. Another study conducted in some selected villages in Darjeeling districts by Ghosh M. ${ }^{3}$ reveals that only $18.5 \%$ of the population were covered by some form of health insurance and a large portion of the population is still financing health care expenditure out of pocket. Awareness regarding health insurance among the population will increase acceptance of health insurance policies, which will decrease out-of-pocket expenses for health care. 
Literature regarding awareness on health insurance in Manipur is lacking. Thus, this study was conducted aiming to determine the level of awareness as well as the perception and practice about health insurance among an urban population.

\section{MATERIALS AND METHODS}

This was a cross-sectional study conducted among 201 families (After sample size calculation) in Thangmeiband Sinam Leikai, Imphal West, Manipur, between $13^{\text {th }}$ Oct and $11^{\text {th }}$ Nov 2014. It was predominantly an urban community. Participants were either head of the family or any responsible adult member of the family above the age of 18 years. Those family who refused to give consent or those in which no eligible members were present at the time of visit were excluded from the study. Ethical approval was obtained from the Institutional Ethics Sub-Committee, Regional Institute of Medical Sciences, Imphal. Informed verbal consents were taken from the participants before the start of the interview.

\section{Sample Size}

Sample size was calculated based on the formula, $\mathrm{N}=\mathrm{Z}^{2} \mathrm{P}(1-\mathrm{P}) / \mathrm{L}^{2}$ where,

$\mathrm{Z}=1.96$ at $95 \%$ confidence interval.

$\mathrm{P}$ (Prevalence of the primary outcome, i.e. awareness about health insurance) $=64 \%$ (taking reference from a study in Mangalore city by Reshmi B et al. where awareness about health insurance among the respondents were $64 \%$ ).

$\mathrm{L}$, the absolute allowable error is taken as 7 ( $\sim 10 \%$ of $\mathrm{P})$.

The calculated sample size comes out to be 181 . Estimating a non-response rate of $10 \%$, the final sample size was 199. A convenience sampling was done. We used a semistructured questionnaire, which was developed by the study team taking into consideration the relevant points. Pretesting was done and necessary modifications were made before it was finalised. The questionnaire comprised of four sections. Section A deals with socio-demographic characteristics, Section B, C and D asked about awareness, attitude and practice about health insurance respectively. Data collected were checked for consistency and completeness. Data entry and analysis was done using SPSS version 21 (IBM). Descriptive statistics like percentage, mean and standard deviation were used. Chi square test and t-test were used to see the association between awareness on health insurance with selected variables.

\section{RESULTS}

A total of 201 families were interviewed between Oct 13 and Nov 11, 2014. Majority (58.7\%) of the respondents were in the age group 35 to 54 years followed by 25 to 34 years (15.9\%) and 55 to 64 years $((13.9 \%)$. Males constitute $76.3 \%$ of the respondents. Majority (98\%) of the respondents were Hindu. About $38.8 \%$ of the respondents were graduates. About $29.8 \%$ of the respondents were Govt. employees followed by businessman (25.4\%). Majority of the respondents (69.1\%) belong to nuclear type of family and majority (84.6\%) had 4 to 7 family members. Majority (82.6\%) of the respondents belong to higher socio-economic status group (SES I and II).

Monthly family income of the respondents vary from Rs. 3000 to Rs. 5,00,000 with a mean income of Rs 35701.49. Annual medical expenditure ranges from Rs. 500 to Rs. $1,20,000$ with a mean of Rs. 13,254 . About $53.7 \%$ of the respondents were enrolled in any form of insurance; $62.7 \%$ of the respondents were aware of health insurance and the major source of information about health insurance were provided by friends and relatives (33.8\%) followed by insurance agents (26.9\%). About $78.6 \%$ of those who were aware of health insurance stated that the benefit of health insurance was mainly monetary assistance at the time of hospitalisation. About $91.5 \%$ of the respondents expressed that they manage their financial needs during medical emergencies from their own pocket, whereas the remaining $8.5 \%$ did so by borrowing. About $85.6 \%$ of the respondents think that health insurance would be able to address the financial needs in times of medical emergencies.

About $85.1 \%$ of the respondents felt that health insurance should be made compulsory for everyone. Majority $(80.1 \%)$ of the respondents preferred Government Health Insurance and the reason they cited was $-62.7 \%$ think it was more reliable and $34.8 \%$ said the premium amount was cheaper. Only $9.9 \%$ of the respondents preferred private health insurance, because they felt that it was more reliable and formal procedures were faster. Only $6 \%$ of the respondents or $9.5 \%$ of those who were aware of health insurance had an existing health insurance policy and all covers family members also. About $91.7 \%$ were private health insurance policy and the annual premium paid ranges from Rs. 1601 to Rs. 30,000 with a mean premium of Rs. 19716.75 .

Educational level and Socio-economic status of the respondents were found to be significantly associated with awareness on health insurance; $69.8 \%$ of the respondents who were above $10^{\text {th }}$ standard were aware of health insurance as compared to $46.8 \%$ who were below $10^{\text {th }}$ standard. Those in higher socio-economic status (SES I and II) had higher awareness on health insurance $(73.1 \%$ and $56.2 \%)$ as compared to those in lower socio-economic status (SES III, IV and V), which was only $48.6 \%$. Occupation, type of family and gender of the respondents were not found to be significantly associated with awareness on health insurance.

\begin{tabular}{|c|c|}
\hline Characteristics & N (\%) \\
\hline \multicolumn{2}{|l|}{ Age Class (Years) } \\
\hline Upto 24 & $4(2.0)$ \\
\hline $25-34$ & $32(15.9)$ \\
\hline $35-44$ & $47(23.4)$ \\
\hline $45-54$ & $71(35.3)$ \\
\hline $55-64$ & $28(13.9)$ \\
\hline 65 and above & $19(9.4)$ \\
\hline \multicolumn{2}{|l|}{ Gender } \\
\hline Male & $148(76.3)$ \\
\hline Female & $53(26.4)$ \\
\hline \multicolumn{2}{|l|}{ Religion } \\
\hline Hindu & $197(98.0)$ \\
\hline Christian & $2(1.0)$ \\
\hline Others* & $2(1.0)$ \\
\hline \multicolumn{2}{|l|}{ Educational Qualification } \\
\hline Illiterate & $6(3.0)$ \\
\hline Primary & $8(4.0)$ \\
\hline Secondary & $48(23.9)$ \\
\hline Higher secondary & $40(19.9)$ \\
\hline Graduate & $78(38.8)$ \\
\hline Post graduate and higher & $21(10.4)$ \\
\hline \multicolumn{2}{|l|}{ Occupation $^{* *}$} \\
\hline Govt. employees & $60(29.8)$ \\
\hline Business & $51(25.4)$ \\
\hline Housewife & $30(14.9)$ \\
\hline Retd. Govt. Employees & $13(6.5)$ \\
\hline Farmer & $6(3.0)$ \\
\hline
\end{tabular}




\begin{tabular}{|c|c|}
\hline Others & $41(20.4)$ \\
\hline Type of Family & $139(69.1)$ \\
Nuclear & $62(30.8)$ \\
\hline oint & $18(8.9)$ \\
\hline Total No. of Family Members & $170(84.6)$ \\
\hline Upto 3 & $13(6.5)$ \\
\hline $4-7$ & Above 7 \\
\hline Table 1: Socio-Demographic Characteristics of the \\
Respondents (N=201) \\
\hline
\end{tabular}

*Includes Muslim, Donyi Polo (A local religion in Arunachal Pradesh).

**Post hoc classification after analysing the responses.

\begin{tabular}{|c|c|}
\hline $\begin{array}{c}\text { Socio-Economic } \\
\text { Status }\end{array}$ & N (\%) \\
\hline I & $93(46.3)$ \\
II & $73(36.3)$ \\
II & $23(11.4)$ \\
V & $11(5.5)$ \\
Table 2: Socio-Economic Status of the Respondents \\
according to Modified BG Prasad SES Classification \\
revised, May 2014.
\end{tabular}

\begin{tabular}{|c|c|}
\hline $\begin{array}{c}\text { Awareness about Health } \\
\text { Insurance }\end{array}$ & N (\%) \\
\hline Aware & $126(62.7)$ \\
Not aware & $75(37.3)$ \\
\hline \multicolumn{2}{|c|}{ Source of Information about Health Insurance* } \\
\hline Friends/Relatives & $68(33.8)$ \\
Insurance agents & $54(26.9)$ \\
Television & $25(12.4)$ \\
Newspaper & $21(10.4)$ \\
Radio & $9(4.5)$ \\
Doctor & $3(1.5)$ \\
Internet & $1(0.5)$ \\
Others & $4(2.0)$ \\
\hline \multicolumn{2}{|c|}{ Table 3: Awareness about Health Insurance and Major } \\
Source of Information about Health Insurance \\
\hline
\end{tabular}

*Multiple Response

\begin{tabular}{|c|c|c|}
\hline \multirow{2}{*}{$\begin{array}{c}\text { Reasons for not } \\
\text { Having Health } \\
\text { Insurance Scheme }\end{array}$} & $\begin{array}{c}\text { Lack of awareness } \\
\text { No idea whom to } \\
\text { approach }\end{array}$ & $107(56.6)$ \\
\cline { 2 - 3 } & Didn't get chance & $14(25.4)$ \\
\cline { 2 - 3 } & Others & $20(10.4)$ \\
\hline $\begin{array}{c}\text { Willing to } \\
\text { Join Health Insurance } \\
\text { Scheme in Future }\end{array}$ & Yes & $158(83.6)$ \\
\cline { 2 - 3 } & No & $31(16.4)$ \\
\hline
\end{tabular}

Table 4: Reasons for not having Health Insurance Scheme and Willingness to Join ( $N=189$ )

\begin{tabular}{|c|c|c|c|}
\hline \multirow[t]{2}{*}{ Characteristics } & \multicolumn{2}{|c|}{$\begin{array}{c}\text { Awareness on Health } \\
\text { Insurance }\end{array}$} & \multirow{2}{*}{$\begin{array}{c}P- \\
\text { value }\end{array}$} \\
\hline & Yes & No & \\
\hline $\begin{array}{c}\text { Educational Status } \\
\text { Upto class } 10 \\
\text { Above class } 10\end{array}$ & $\begin{array}{c}29((46.8) \\
97(69.8)\end{array}$ & $\begin{array}{l}33(53.2) \\
42(30.2)\end{array}$ & $0.002^{*}$ \\
\hline $\begin{array}{l}\text { Occupation } \\
\text { Govt. employee } \\
\text { Business } \\
\text { Others. }^{a} \\
\end{array}$ & $\begin{array}{l}42(70.0) \\
31(60.8) \\
53(58.9)\end{array}$ & $\begin{array}{l}18(30.0) \\
20(39.2) \\
37(41.1)\end{array}$ & $0.367 *$ \\
\hline $\begin{array}{c}\text { Socio-Economic Status. }^{\mathbf{b}} \\
\text { I } \\
\text { II } \\
\text { III, IV \& V } \\
\end{array}$ & $\begin{array}{l}68(73.1) \\
41(56.2) \\
17(48.6) \\
\end{array}$ & $\begin{array}{l}25(26.9) \\
32(43.8) \\
18(51.4)\end{array}$ & $0.013^{*}$ \\
\hline
\end{tabular}

\begin{tabular}{|c|c|c|c|}
\hline $\begin{array}{c}\text { Gender } \\
\text { Male } \\
\text { Female }\end{array}$ & $\begin{array}{c}92(62.2) \\
34(64.2)\end{array}$ & $\begin{array}{l}56(37.8) \\
19(35.8)\end{array}$ & $0.797^{*}$ \\
\hline $\begin{array}{c}\text { Type of Family } \\
\text { Nuclear } \\
\text { Joint }\end{array}$ & $\begin{array}{l}84(60.4) \\
42(67.7)\end{array}$ & $\begin{array}{l}55(39.6) \\
20(32.3)\end{array}$ & $0.322^{*}$ \\
\hline $\begin{array}{c}\text { Mean Per Capita } \\
\text { Monthly Income (In Rs) }\end{array}$ & 8078.8 & 4945.6 & $0.001^{* *}$ \\
\hline \begin{tabular}{|} 
Table 5: Association between Awareness on Health Insurance \\
with Certain Socio-Demographic Variables
\end{tabular} \\
\hline
\end{tabular}

a-Includes retired Govt. employees, farmers, housewife, etc. b-Socio-economic status according to modified BG Prasad May, 2014. ${ }^{*}$ Chi square test. ${ }^{* *}$ Independent sample t-test.

\section{DISCUSSIONS}

The present study was an attempt to determine the level of awareness as well as the enrolment of health insurance among an urban community in Imphal. In our study, about $62.7 \%$ of the respondents were aware about health insurance. This finding was similar to the findings by Reshmi B et al. $^{2}$ and Choudhary ML et al. ${ }^{5}$ where awareness about health insurance among the respondents were $64.0 \%$ and $57.25 \%$ respectively. In another study by Priyadarsini SP and Ethirajan N. ${ }^{6}$ among selected rural and urban population of Chidambaram, Tamil Nadu only $47.6 \%$ in urban and $28.6 \%$ in rural were aware about health insurance. This variation in the awareness level may be attributed to the higher proportion of population in the higher socioeconomic status and educational level in our study population as compared to the study by Priyadarsini SP and Ethirajan N. ${ }^{6}$ However, in another by Gowda $S$ et al. ${ }^{7}$ conducted among rural population in South India, awareness about health insurance were high (81\%).

Friends and relatives (33.8\%) as well as insurance agents $(26.9 \%)$ were the major source of information about health insurance in our study. Similar findings were also observed in the study by Choudhary ML et al. 5 where family/friends/relatives/colleagues (38\%) were the primary source of information followed by insurance agents (27.5\%). However, in a study by Priyadarsini SP and Ethirajan N.6, television played a major source of information about health insurance among selected rural and urban population of Chidambaram, Tamil Nadu. In another study by Yellaiah J. ${ }^{8}$ in Hyderabad city, newspaper (38.8\%) were the major source of information about health insurance.

In our study no significant associations were found between gender, type of family and occupation of the respondents with awareness about health insurance. This was in contrast to the findings by Choudhary ML et al. ${ }^{5}$ in Jamnagar district where significant associations were found between gender and occupation of the respondents with awareness on health insurance. In another study by Kumabam RS et al. ${ }^{9}$ conducted in Imphal city, awareness among males (53.7\%) were found to be significantly higher as compared to females (24\%). Only about $9.5 \%$ of the respondents who were aware about health insurance had an existing health insurance scheme in our study. This was in contrast to the findings in the study by Ghosh M. ${ }^{3}$ in Darjeeling district, where $54 \%$ of respondents who were aware about health insurance subscribe to health insurance scheme. However, in a study by Madhukar S et al. ${ }^{10}$ conducted in rural Bangalore, only $22 \%$ of the households had health insurance coverage. The very low percentage of enrolment in our study indicates the need to convince people about the benefits of health insurance. The 
fact that more than $90 \%$ of those who subscribe to a health insurance scheme were in private health insurance scheme highlights the lack of people oriented public health insurance scheme in Manipur. In our study about $83.6 \%$ of the respondents who did not have any existing health insurance policy were willing to join one after they were explained about the benefits of health insurance scheme. Moreover, about $80.1 \%$ of them preferred government health insurance scheme. These emphasized the need of the government to come up with a health insurance scheme that will address the financial needs of the people during illness, particularly the poor and the needy.

This study is probably one of the few study to find out the level of awareness about health insurance among an urban community in Manipur. Our adequate sample size and the method of conducting the study by interviewing can be regarded as one of the strength of the study since the respondents can be probed further to assess their awareness and perception about health insurance.

\section{LIMITATIONS}

As the interview was done mostly during office hours (Between 10.00 a.m. to 3.00 p.m.), majority (60\%) of the respondents were non head of the family. Although almost all of the respondents were responsible members of the family, however, their awareness about health insurance may not be representative of the family as most of the decision makers of the family were left out. The way we select our sample raise some doubt regarding generalizability to other similar population.

\section{CONCLUSIONS}

To conclude, awareness about health insurance in our study population was fairly good, but it did not lead to increased enrolment. These calls for the need to reinforce information, education and communication campaign about health insurance among the general population. Moreover, government also needs to come up with a comprehensive health insurance scheme, which covers everyone irrespective of socio-economic status so that more people subscribe to health insurance scheme. This will ultimately lessen their financial burden in times of major illness.

\section{ACKNOWLEDGMENTS}

The authors wish to thank Dr. Deepen Chettri, Dr. Morung Dangsawa, Dr. DJ Lalneiruol, Dr. Deepak Naorem, Dr. Bimarsh Gautam, Dr. Devkiswar Thingnam and Dr. Irom Amrita for their help during the various stages of the study. The authors also like to express gratitude to Mr. Rajen for his help during the study.

\section{REFERENCES}

1. Report of the national commission on macro-economics and health. Ministry of Health and Family Welfare, Govt. of India, 2005.

2. Reshmi B, Sreekumaran NN, Sabu KM, et al. Awareness of health insurance in a south Indian population-a community-based study. Health and populationperspectives and Issues 2007;30(3):177-88.

3. Ghosh M. Awareness and willingness to pay for health insurance: a study of Darjeeling district. IOHR JHSS 2013;12(1):41-7.

4. Shankar RD, Kumar ARK, Prabhu RG. Prasad's Socioeconomic classification-an update for 2014. IJRHS 2014;2(3):875-8.

5. Choudhary ML, Goswami KI, Khambati SB, et al. Awareness of health insurance and its related issues in rural areas of Jamnagar district. Natl J Community Med 2013;4(2):267-71.

6. Priyadarsini SP, Ethirajan N. KAP on health insurance among selected rural and urban population of chidambaram, Tamil Nadu. Int J Pharmaceutical \& Biological Archives 2012;3(4):838-41.

7. Gowda S, Manjunath C, Krishna D. Awareness about health insurance in rural population of South India. Int $\mathrm{j}$ Community Med Public Health 2015;2(4):648-50.

8. Yellaiah J. Awareness of health insurance in Andhra Pradesh, Hyderabad. Int J Sci Res Publicat 2012;2(6):1-6.

9. Rajesh SK, Ibohal MC, Sureshkumar S, et al. Customer perception of health insurance products: a study in Imphal city, Manipur. IJM 2013;4(3):82-95.

10. Madhukar S, Sudeepa D, Gaikwad V. Awareness and perception regarding health insurance in Bangalore rural population. IJMPH 2012;2(2):18-22. 